\title{
Ethical decision making in pain management: a conceptual framework
}

This article was published in the following Dove Press journal: Journal of Pain Research

\begin{abstract}
Ana Sofia Carvalho, ${ }^{1-3}$ Sandra Martins Pereira, ${ }^{1-3}$ António Jácomo, ${ }^{1-3}$ Susana Magalhães, ${ }^{1,2,4}$ Joana Araújo, ${ }^{1-3}$ Pablo HernándezMarrero, ${ }^{1-3}$ Carlos Costa Gomes, ${ }^{1-3}$ Michael E Schatman ${ }^{5,6}$

'Instituto de Bioética, Universidade Católica Portuguesa, Porto, Portugal; ${ }^{2}$ UNESCO Chair in Bioethics, Universidade Católica Portuguesa, Porto, Portugal; ${ }^{3}$ CEGE:

Centro de Estudos em Gestão e Economia (Research Centre in Management and Economics), Católica Porto Business School, Universidade Católica Portuguesa, Porto, Portugal; ' ${ }^{4}$ Universidade Fernando Pessoa, Porto, Portugal; ${ }^{5}$ Research and Network Development, Boston Pain Care, Waltham, MA, USA; 'Department of Public Health and Community Medicine, Tufts University School of Medicine, Boston, MA, USA
\end{abstract}

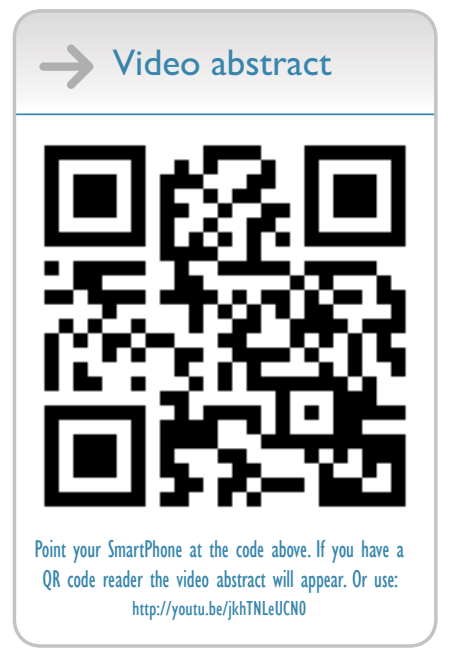

Correspondence: Ana Sofia Carvalho Instituto de Bioética, Universidade Católica Portuguesa, Rua Diogo Botelho 1327, 4169-005 Porto, Portugal

Tel +351226196216

Fax +351 226196291

Email acarvalho@porto.ucp.pt
Introduction: The practice and study of pain management pose myriad ethical challenges. There is a consensual opinion that adequate management of pain is a medical obligation rooted in classical Greek practice. However, there is evidence that patients often suffer from uncontrolled and unnecessary pain. This is inconsistent with the leges artis, and its practical implications merit a bioethical analysis. Several factors have been identified as causes of uncontrolled and unnecessary pain, which deprive patients from receiving appropriate treatments that theoretically they have the right to access. Important factors include (with considerable regional, financial, and cultural differences) the following: 1) failure to identify pain as a priority in patient care; 2) failure to establish an adequate physician-patient relationship; 3) insufficient knowledge regarding adequate prescription of analgesics; 4) conflicting notions associated with druginduced risk of tolerance and fear of addiction; 5) concerns regarding "last-ditch" treatments of severe pain; and 6) failure to be accountable and equitable.

Objective: The aim of this article was to establish that bioethics can serve as a framework for addressing these challenging issues and, from theoretical to practical approaches, bioethical reflection can contextualize the problem of unrelieved pain.

Methods: This article is organized into three parts. First, we illustrate that pain management and its undertreatment are indeed ethical issues. The second part describes possible ethical frameworks that can be combined and integrated to better define the ethical issues in pain management. Finally, we discuss possible directions forward to improve ethical decision making in pain management.

Discussion: We argue that 1) the treatment of pain is an ethical obligation, 2) health science schools, especially medical training institutions, have the duty to teach pain management in a comprehensive fashion, and 3 ) regulatory measures, which prevent patients from access to opioid treatment as indicated in their cases, are unethical and should be reconsidered.

Conclusion: Developing an ethical framework for pain management will result in enhanced quality of care, linking the epistemic domains of pain management to their anthropological foundations, thereby making them ethically sound.

Keywords: bioethics, pain management, ethical decision making, ethics of care, narrative medicine, patient-centered care

\section{Introduction}

The practice and study of pain management pose numerous ethical challenges. ${ }^{1}$ Twenty years ago, $\mathrm{Cassel}^{2}$ described how medicine's singular focus on curing the diseases of the body precluded it from being able to attend to the suffering of the individual. His core insight "persons suffer, bodies do not" has major explanatory power for medicine's neglect of human pain. It is true that if medicine can delineate the physical/biological 
pain as its domain/responsibility and leave the rest to other professionals, then medicine can insulate itself from the responsibility to acknowledge and respond to pain and suffering resulting from a patient's experience of illness. ${ }^{3}$ Since such insulation is generally not possible, we are faced with an ethical dilemma. ${ }^{4}$

Pain management faces a number of difficult ethical questions, which are perhaps too numerous to elucidate. The questions include: What importance does pain have in medicine? What role does pain management play in the clinical care of patients? What duties do health care professionals have concerning the pain of their patients? What other duties must be balanced against the duty to provide adequate analgesia?

This article posits that bioethics can make important contributions to solving these challenging issues. From theoretical to practical approaches, bioethical reflection can illuminate the problem of unrelieved pain. This article is organized into three parts. First, we illustrate that pain management and its neglect constitute ethical issues. Second, we describe potential ethical frameworks that can be combined and integrated to shape and organize some of the critical ethical issues in pain management. Finally, we discuss possible directions forward that will hopefully improve ethical decision making in pain management.

\section{The facts}

Pain is a common symptom in clinical practice, placing special demands on health care professionals as well as the patients they treat. ${ }^{5}$ Knowledge of pain (as a symptom, disease, and/or illness and phenomenon, ie, total pain) must be the basis for all constructs in pain medicine. ${ }^{6-11}$ Due to the incredible complexity of pain, the treatment of patients with refractory pain is also complex and, accordingly, can be demanding. The clear articulation of pain medicine can be challenging, especially considering the current economic, legal, and social environments.

Two phenomena regarding pain management are indisputable. First, health care professionals have an ethical obligation to relieve pain. ${ }^{12}$ Second, this obligation has been largely neglected. ${ }^{4}$ All types of pain (eg, traumatic, postoperative, chronic, non-cancer, cancer, and end of life) remain largely untreated and undertreated. Several studies have illuminated this problem: $80 \%$ of patients who undergo surgical procedures experience acute postoperative pain, and $\sim 75 \%$ of those with postoperative pain report the severity as moderate, severe, or extreme. ${ }^{13}$ An inordinately large proportion of nursing home residents are estimated to experience pain daily in nursing homes ranging from $40 \%$ to
$85 \%$, with as many as $25 \%$ of these older adults receiving no intervention for pain relief. ${ }^{14}$ Pain is highly prevalent among nursing home residents with moderate-to-severe dementia $(61.5 \%)$, and only $30.7 \%$ of patients were treated with analgesic drugs. ${ }^{15}$ Even at the end of life, the data regarding adequate pain management remain discouraging; nearly one of two patients with cancer pain is undertreated; ${ }^{16-19}$ there is significant disparity in pain treatment adequacy with the odds of undertreatment twice as high for minority patients, ${ }^{13}$ and more than $65 \%$ of nursing home residents with cancer had pain. ${ }^{20}$ So widespread are the stories of unrelieved pain at the end of life that some believe that public support for euthanasia or physician-assisted suicide is driven by the fear of dying in pain. ${ }^{4}$

Various barriers to effective pain management (relief of pain and suffering as well as improvement in function and quality of life) have been described in the literature: 1) failure of physicians to identify pain as a priority in patient care, which relates to the prevalence of the curative model over a person-centered care paradigm as well as the dominance of the scientific approach over the humanistic approach; ${ }^{21} 2$ ) failure of physicians to develop adequate relationships with their patients, which threatens the possibility of understanding the subjective language of pain; ${ }^{22} 3$ ) insufficient knowledge regarding pain management; $;^{3,23-25}$ 4) fears associated with opioid prescription and utilization for pain relief (eg, addiction, tolerance, dependence, and adverse side effects); ${ }^{3,25-27}$ 5) failure of health care systems to hold clinicians accountable for pain relief;, $3,26,28$ ) patients' and family members' resistance to using opioids; ${ }^{23,29} 7$ ) the "war on drugs and addiction" 4 and the consequent "pendulum swing";30,31 and 8) cost constraints. ${ }^{3,26,32}$

Diverse problems have been described in the pain management literature that, in our opinion, strengthens the importance of an ethical analysis. Evidence suggests the following: the undertreatment of pain is a reality ${ }^{6}$ and the prevalence and societal burden of chronic pain are underestimated; treatment is not always instituted and/or adequate; ${ }^{33}$ the inappropriate overutilization of pharmacologic agents and techniques without assuming a holistic approach toward pain management; ${ }^{6,33}$ and the tensions and conflicts that can occur between the stakeholders involved in pain medicine at all levels (micro-meso-macro). ${ }^{34-38}$

\section{Ethical decision making in pain management}

How we think about pain exerts an influence on the manner in which we respond to it. Our ability and willingness to hear, 
detect, trust, treat, and report which rely, to an extent, on our understanding of the essence and meaning of pain come ideally from a phenomenological perspective. ${ }^{39,40}$ Thus, how we think about pain is ideally guided by those unspoken and unconscious assumptions, myths, and metaphors that shape our understanding of the individual sufferer's reality and experience of pain. Any effort to improve pain management will necessitate working not only at institutional, regulatory, and policy levels but also, simultaneously and explicitly, at the conceptual one.

The practice of medicine and, more broadly, health care is theoretically an ethical enterprise. ${ }^{3}$ Indeed, the relief of all forms of pain and suffering is an ethical duty of health care professionals and societies as well and has been recognized throughout the world as an ethical demand and human right. ${ }^{41-44}$ The patient should be the primary interest of medicine and physicians are obliged to act first and foremost in the best interest of their patients. ${ }^{45}$ Determining the "good" is the work of ethics, entailing the implementation of decision-making processes. ${ }^{6}$

Nonetheless, there seems to be a failure of many health care systems to hold clinicians accountable for pain management. ${ }^{3}$ Physicians and other health care professionals, organizations, systems, and societies fail to provide both effective pain management and holistic care. This denotes an alarming failure of medical professions to recognize the ethical implications of undertreated pain and the unnecessary suffering that it engenders. ${ }^{3}$

From our perspective, an overview of the existing ethical theories is needed to ensure the sound ethical reasoning and judgment required for adequate pain management. Theories differ according to which aspect of the ethical situation they assume as the focus of their attention. The agent, the action itself, the consequences of the action, the relationships of the agent, and the specific characteristics of the situation have all been the focus of one or more ethical theories. Taking into consideration the specific case of pain management, integrating distinct approaches needs to be considered to better structure the main ethical dimension and framework of pain management: 1) an ethics of care, with a particular focus on the physician-patient relationship as a therapeutic alliance using a narrative-based ethics that takes into consideration the subjective dimensions of language pertaining to pain and 2) the ethical framework of the so-called principlism.

\section{The importance of care-based ethics}

Patient-physician relationships can be categorized into three main models: 1) paternalistic, deliberative, interpretive, informative; ${ }^{46}$ 2) paternalistic, shared, informed; ${ }^{47}$ and 3 ) patient-active, collaborative, passive. ${ }^{48}$ As physician and patient endeavor to exchange information, emotions can dominate the clinical encounter, and the traditional models may not address this emotional exchange. In fact, in a humanistic approach, this dialogical task is strongly about ethics; this ethics encounter fosters the capacity of physicians to see themselves as a character in others' stories. ${ }^{49}$ Thus, physicians relying on the traditional models of care may fail in treating those patients who have emotionally distressing symptoms..$^{50}$ Regardless of the model of patientphysician dyad, this relationship is ideally characterized by a therapeutic alliance between the one suffering (vulnerable) and the one caring (responsible). The development of such a relationship requires cognitive skills, emotional preparation, and reflective capacity. However, since the "curative model" in modern medical education and practice remains prominent, the development of these types of skills remains challenging and uncharacteristic. Therefore, an approach on care-based ${ }^{49,51,52}$ as well as virtue-based ethics ${ }^{53-55}$ may be envisaged as potential guides for answers to this type of problem. In our opinion and as stated by Benner, ${ }^{56}$ the major point of contrast between virtue- and care-based ethics lies in the manner in which virtues are manifested. In virtue-based ethics, the point of scrutiny lies in the inner character of the actor, whereas in care-based ethics, the focus is relational, ie, how virtues are lived out in specific relationships, particularly unequal relationships in which certain members are vulnerable. Accordingly, pain and its optimal management challenge the defiant straddling of the mind-body dualism characteristic of this curative model that persists in much of Western culture.

In fact, the curative model, immersed in the biases of dualism in medicine, has been the subject of critique, as it appears to create a hostile environment for the ideal care of severely ill and dying patients. ${ }^{3}$ Often, the curative model of care is perceived as "competing" with that of person-centered care, as if these two models should or could represent completely separate and distinct realms. ${ }^{3}$ More recent perspectives emphasize the need for integration ${ }^{57}$ with pain management and palliative care being considered simultaneously as an approach and a specialist area of care provision. The ideal paradigm requires the integration of the main principles, values, and practices of palliative care with those of personcentered care in all forms, areas, and settings. ${ }^{58-61}$

Commonly utilized diagnostic tests cannot communicate the intensity, duration, quality, and personal dimensions of pain, as they are something that only the sufferer can 
appreciate. ${ }^{40}$ Ideally, physicians observe, listen to, and trust the patient's narrative of pain and talk with the patients, which are skills that physicians are not necessarily taught in their formal training.

Physicians do not trust (hence, hear) the human voice[...] they in effect perceive the voice of the patient as an unreliable narrator of bodily events, a voice which must be bypassed as quickly as possible so that they can get around and behind it to the physical events themselves. ${ }^{4}$

Therefore, an "ethics of care" is crucial to foster a relationship-based ethics, based on an "emotional commitment and willingness to act on behalf of persons with whom one has a significant relationship" 62 that focuses on empathic association rather than solely on individual rights. This "ethics of care" is relevant to pain management because it challenges impartiality and detachment, as well as universal principles in ethics, as an important component of the therapeutic alliance. Total pain and suffering, in particular, may be perceived best in an empathic relationship characterized by a rich narrative interchange, which calls attention to consideration of the importance of narrative-based ethics.

\section{The importance of narrative-based ethics}

Modern medical practices have, at times, abstracted the problem of pain from its context and story. Therefore, from our perspective, another important ethical theory through which to frame pain management is narrative-based ethical theory. In this article, the story of the individual case becomes of core importance and of paramount understanding. The subjectivity of pain makes communication essential to its management and relief.

"Physical pain - unlike any other state of consciousness has no referential content. It is not of or for anything". ${ }^{63}$ The task of describing pain lends itself to the use of metaphors, allowing it to take the shape of something with a more familiar exterior, such as a "sharp nail" or "hot flame."4 Unless one is its “owner," little about pain lends credence to its existence. Although people may display signs of pain (eg, a grimaced face, an absent appetite, and an irritable disposition), these remain signs of something interior and something not necessarily easily described by the one in pain nor easily believed by those who do not experience it. This is especially true if they, as care givers, are not familiar with the practical guides for the assessment of the existence of pain and its accurate evaluation. Pain has been described as having an invisible geography that has no reality because it has not yet manifested itself on the visible surface of the earth. ${ }^{39}$ The experiential gap between the bearer of pain and the observer is so wide that it is said to have an epistemic impact. In other words, as stated by Scarry ${ }^{63}$ that "to have pain is to have certainty; to hear about it is to have doubt." The believability of pain is confounded by its subjectivity, as it is often the case with subjective experience. Pain cannot be generalized on the basis of objective factors that signal a particular therapeutic response. Each individual experiences pain quite differently, depending on factors as variable as neurobiology, culture, religious beliefs, previous experiences of pain, and current psychological and spiritual states of feeling.

Narrative medicine ${ }^{64}$ stands out as a logical pathway for integration in pain management, as it aims to address each individual patient's experience as a source of data and a resource through which to better attend and understand the pain condition. It requires the collection of patients', caregivers' and health care professionals' stories both to provide patients with more effective care and foster shared decision making. The stories told by all stakeholders and the practice of reflective writing and closed reading set up a common ground of shared expectations, fears, and doubts. These can provide privileged access to the inner world of those who suffer and those who care. ${ }^{65}$ By emphasizing this first-person narrative, the entirety of the person in pain can be considered, rather than simply focusing on signs and symptoms.

However, narrative-based ethical theories are not without limitations. Because they are so rich with respect to the individual case, it becomes more difficult to generalize across cases. How does one develop policies tied to narratives ${ }^{24}$ Principle-based ethical theories, that are further described, can offer a structured means of solving conceptual and bioethical problems, creating a template to aid in the making of complex and difficult decisions. Nonetheless, they need some bottom-up, case-based supplementation through casuistry narrative methods. ${ }^{24}$ These top (principles) to/from the bottom (narratives) can indeed only be realized through a care approach between the physician and the patient. In fact, as previously claimed by other authors (including Vanlaere and Gastmans ${ }^{51}$ ), care can hardly be the only point of departure of an ethical perspective and needs to be complemented with universal principles to possess the normativity that is characteristic of a full ethical perspective; care starts from a sentiment, which is required for one to act in an ethically responsible way. However, without the addition of principles that link this sentiment to a "universal ethical standard" (such as justice), arbitrariness and favoritism will lurk. 


\section{Relevant ethical principles in pain management}

Health care professionals must seek to provide biomedical, technical, and scientific goods in ways that allow adequate appreciation for patients' values, goals, and choices and convey respect for the patient as a person. ${ }^{6,66} \mathrm{An}$ applied ethics of pain medicine must be pragmatic and therefore cannot rely upon or be reduced to a single principle or ethical system. ${ }^{6}$

There exists a broadly based humanistic ethics, which applies to the domain of medical care giving patients a strong prima facie right to freedom from unnecessary pain. Such an approach places two concomitant moral obligations toward patients upon medical professionals. First, there is a responsibility not to inflict additional pain and suffering beyond that which is absolutely necessary (primum non nocere). ${ }^{55}$ Second, there is the responsibility to do all than can be performed within the current limits of knowledge and available resources to relieve pain and suffering. ${ }^{67}$ Responsibility and accountability at micro (individual, health care professionals), meso (interprofessionals, teams, health care and education organizations), and macro (health care systems, education systems, policies such as pain as the fifth vital sign) levels are paramount. Indeed, personal and professional responsibility/ accountability for failing to treat patients competently and compassionately is critical, as it is to create environments that make effective care for patients in pain the norm. ${ }^{68}$ This dual connection between responsibility and accountability must take other bioethical principles into consideration, as well: autonomy, vulnerability, integrity, dignity, and justice.

Unrelieved pain may leave patients extremely vulnerable, speechless, changed, and even destroyed. In common medical ethics parlance, unrelieved pain can compromise a person's autonomy and increase vulnerability, ${ }^{69}$ whereas providing pain relief can potentially protect a person's integrity and promote dignity. The consent process, for example, demonstrates respect for patients' values and decision-making capacities. However, autonomy can be compromised in a suffering person when provider goals are directed by the immediate needs of the sick body or by the compulsion to address what is perceived to be the source of suffering. This issue should be taken into account when caring for a patient in pain. ${ }^{2}$ Regrettably, the term "vulnerable" too often is used without any concrete meaning. Given the absence of commonly accepted standards for the identification and solution to the issue of vulnerability, a list of six types of vulnerability has been proposed: cognitive, juridical, deferential, medical, allocational, and infrastructural ${ }^{63}$ These six types of vulnerability might also represent an ethically relevant feature that bespeaks vulnerability in the context of pain care. ${ }^{70,71}$

Physicians have a duty to take positive steps to help others, which goes beyond simply refraining from harmful acts. In fact, health care professionals who witness unnecessary pain have an ethical (and also a deontological) responsibility toward those patients, even if they are not clinically responsible for them. ${ }^{72}$ Thus, the further notion that moderate-tosevere pain can be physically and psychologically harmful, treating patients in a holistic fashion will be a more fruitful approach. ${ }^{37,39}$ Patients with pain often become vulnerable and despaired, and therefore at risk of trying anything that alltoo-willing health and non-health practitioners might recommend. When is an aggressive intervention a compassionate and understandable effort as opposed to taking advantage of a vulnerable patient? Given the large multitude of interventions available today for pain management, desperate individuals with unremitting pain may find unqualified and/or greedy practitioners who may take advantage of a patient by performing unnecessary or overly extensive procedures. The practitioner, on the other hand, may believe that he or she is acting in the best interest of the patient, even if the primary motivation of the practitioner is financial. This severely challenges the principle of non-maleficence. ${ }^{67}$

We may recognize the existence of other "vulnerable" groups of patients with pain, such as those who cannot communicate verbally (children, older people, and unconscious patients), end-of-life patients, and socioeconomically disadvantaged patients. This latter group, in particular, tests the ethical principle of justice, conceived as the fair distribution and access to health care for all persons/citizens who need it. ${ }^{62}$

In addition to respecting autonomy, considering vulnerability, preventing harm, and promoting good for patients, physicians have an obligation to promote justice in the distribution of these goods/services. Distributive justice refers to fair, equitable, and appropriate distribution of a privilege, benefit, or service within a society. Problems of distributive justice arise under conditions of scarcity and competition in which there is not enough to provide all that each needs or desires. ${ }^{39}$ As an example, we may argue that currently, financial constrains make it more difficult in almost all systems to provide necessary monitoring of patients (eg, due to work overload, time pressure, and resource shortages), therefore hindering the humanistic and relational approaches is needed to effectively assess, manage, and control pain. In fact, evidence suggests that access to pain control and palliative care is currently grossly inequitable. ${ }^{43}$ Furthermore, the likelihood that the lack of equity will con- 
tinue to increase, particularly in societies in which medicine has become corporatized, ought not to be underestimated..$^{73}$

Western health care systems are dominated by a paradigm that emphasizes "disease" as the basic element of pathology and health care provision. ${ }^{74}$ However, as Osler ${ }^{75}$ recognized, it is more important to know "what sort of patient has a disease (risk factor or adverse effect) than to know what sort of disease a patient has." ${ }^{, 76,77}$ A person-focused or population group-focused (rather than a disease-focused) view of morbidity and pain can ethically reveal and address inequity (ie, the presence of systematically and potentially remediable differences among population groups defined racially, culturally, socially, economically, or geographically). There exists therefore the need to further develop and implement guidelines and approaches that are appropriate to personfocused care rather than to disease-focused care. Obtaining information on the current impact of inequities on access to pain care is a critical initial step toward action, since equitable access to care is of vital importance in all health care systems.

\section{The way forward}

As discussed earlier, the barriers to high-quality pain management are numerous and complex. Often-cited impediments include 1) the lack of education and training on state-of-theart pain management, 2) the lack of institutional mechanisms for standardizing the assessment and treatment of pain, 3) the lack of accountability for the undertreatment of pain, and 4) federal and state statutes and regulations designed to fight a "war on drugs and addiction" that negatively affect the legitimate use of controlled substances. ${ }^{4}$ There is an uncomfortable irony in Blacksher's ${ }^{4}$ prophecy of the deleterious impact of this "war" on patients with pain in 2001 , ie, at a time at which the severity of the harms that are currently being performed to patients by the "war" was not yet being realized. Further strategic actions are needed to improve pain management and provide answers to these problems from an ethical perspective. Three ethical approaches have accordingly been presented in this article. The first pertains to reflection on and analysis of the nature of pain itself. The second is related to pain's personal dimensions. The third refers to the intersubjectivity embedded in the assessment and treatment of pain. All converge on one essential feature of good pain management: attending to the person in pain. ${ }^{4}$

From our perspective, educational interventions that consider the specific nature of pain and the issues previously detailed must be designed for "both" patients and health care professionals to enhance the ethical robustness of pain management. Basic undergraduate education and postgradu- ate education programs are needed to stimulate cognitive skill acquisition, emotional development, and the capacity of reflective insight. ${ }^{78}$ Appropriate competencies for pain management can be promoted by encouraging clinicians to actively engage the humanistic dimensions of medicine and gain insight into their own feelings and attitudes. Even though knowledge does not necessarily translate into actions, using ethical arguments to establish "the good" is often the first step in motivating behavioral change toward such. Strategies for education regarding ethical issues in pain management can provide the proper balance between the essential knowledge and skills of the curative model and those of the personcentered care model. ${ }^{3,78-80}$ This can ensure the development of a more comprehensive paradigm of pain management that recognizes the complexity of pain as a "total" phenomenon and experience. Consequently, this approach accounts for economic factors imposed upon health care systems and enables the articulation of any paradigmatic revision within the contemporary medicolegal environment. ${ }^{6}$

A better understanding of what influences one's interpretation of a person in pain is part of the process of cultivating an ethical sensitivity to the personal dimensions of pain and suffering. Because identifying with the pain of others does not necessarily come naturally to all health care professionals, the pedagogical tools used by medical humanity courses may be especially valuable in efforts to improve the state of pain care. The use of literature, movies, and other art forms can be considered an important tool, as all are designed to stimulate human emotions and the capacity to relate to those living in circumstances very different from one's own. ${ }^{4,39,79,81}$

Dispelling the myriad myths associated with pain and its care will be no easy matter. Part of the solution depends on educating and training health care professionals in the state-of-the-art of pain management. In addition, ethics cases chosen for teaching settings need to reflect a broader array of pain management scenarios. Bioethics, as a field, has been accused of experiencing an aversion to such everyday evils. ${ }^{4}$ Nevertheless, case-based ethics learning approaches might prove to be an invaluable tool in teaching developing professionals who will treat pain.

\section{Conclusion}

Anyone who has personally experienced severe acute or chronic pain will grasp its ethical dimensions and frameworks. However, the challenge to pain management lies on the other side of that experience: moving people not in pain to acknowledge, treat, and care for those who are in pain. In summary, a "patient-centered" view of pain is more accurate 
than a disease-oriented view. This approach is more effective, more efficient, safer, more equitable, and better aligned with the core principles and philosophy of medicine. To diminish inequity and the neglect and marginalization of pain care, health care systems and medicine need to be redefined.

In our opinion, decision-making practices informed by person-centered dimensions (patient as a person, characteristics of the physician, patient-physician communication and relationship) that take into account an array of ethical theories (eg, ethics of care and virtues, narrative medicine/ approach ethics, and principle-based ethics) may constitute a constructive approach to an ethics framework for pain management. Accordingly, as we have proposed a novel ethics of care, this model places a particular focus on the physician-patient relationship as an ethics encounter, using narrative-based ethics approaches that take into consideration the subjective dimensions of language pertaining to pain, and the ethical principles of the so-called principlism. This is of particularly importance given the International Association for the Study of Pain's consideration of 2018 as the global year for excellence in pain education. Accordingly, this framework, which is illustrated in Figure 1, will hopefully

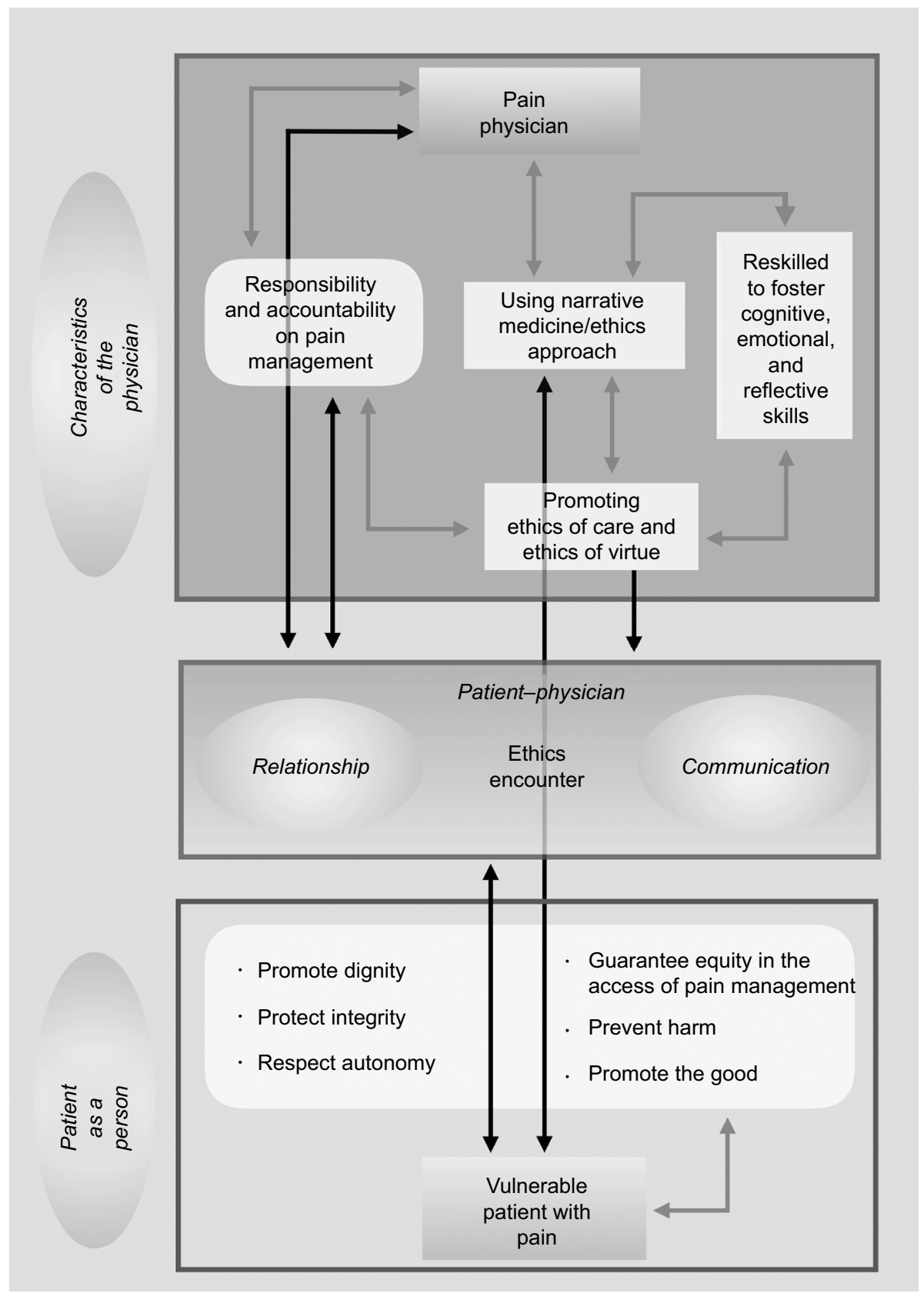

Figure I Integrated ethical framework for pain management. 
contribute to this initiative, motivating and reskilling pain physicians on cognitive, emotional, and reflective skills, rather than just technical ones, with these "nontechnical" skills of particular importance to vulnerable patients with pain. This can be illustrated through a core philosophy of medicine as specific and focal to the uniqueness of pain, of the patient and of the health care professional.

This ethical framework of pain management will allow us to 1) further respect ethical principles (integrity, autonomy, equity, non-maleficence, and beneficence) and, thus, patients' dignity, 2) acknowledge and explain the vulnerabilities illuminated by pain and recognize the variability and subjectivity of its expression through narratives of both patients and physicians, 3 ) reduce asymmetries and thereby improve patient-clinician relationships and communication, and 4) be more fully responsible and accountable for the overall management of pain. Such will result in "good" care, linking the epistemic domains of pain management to its anthropological foundations, and accordingly will be ethically sound.

\section{Acknowledgments}

This article was written during the period of the following projects: InPalIn (Integration of Palliative Care and Intensive Care), NOS (Narrar, Ouvir Sentir), and subproject ETHICS II of project ENSURE (Enhancing the Informed Consent Process: Supported decision-making and capacity assessment in clinical dementia study). Therefore, SMP, PHM, and ASC would like to thank Fundação Grünenthal and Fundação Merck, Sharpe, and Dohme for the funding provided for the project InPalIn. SM, CCG, JA, and ASC would like to thank Fundação Calouste Gulbenkian for the funding provided to the project NOS. PHM, JA, SMP, and ASC would like to thank the Portuguese Foundation for Science and Technology (Fundação para a Ciência e a Tecnologia - FCT) and the EU COFUND ERA-NET Program for the funding provided to the subproject ETHICS II of Project ENSURE. The authors would also like to thank Mr Diogo Morais for the graphical work of Figure 1.

\section{Author contributions}

All authors contributed toward data analysis, drafting and revising the paper and agree to be accountable for all aspects of the work.

\section{Disclosure}

The authors declare that no funding was obtained to conduct this study. The authors report no conflicts of interest in this work.

\section{References}

1. Gallagher RM. Ethics in pain medicine: good for our health, good for the public health. Pain Med. 2001;2(2):87-89.

2. Cassel E. The nature of suffering and the goals of medicine. $N$ Engl $J$ Med. 1982;306(11):639-645.

3 . Rich BA. An ethical analysis of the barriers to effective pain management. Camb Q Healthc Ethics. 2000;9(1):54-70.

4. Blacksher E. Hearing from pain: using ethics to reframe, prevent, and resolve the problem of unrelieved pain. Pain Med. 2001;2(2): 169-175.

5. Murinson BB, Agarwal AK, Haythornthwaite JA. Cognitive expertise, emotional development, and reflective capacity: clinical skills for improved pain care. J Pain. 2008;9(11):975-983.

6. Giordano J, Schatman ME. An ethical analysis of crisis in chronic pain care. Part 1. Facts, issues, and problems in pain medicine. Pain Physician. 2008;11(4):483-490.

7. Giordano J, Schatman ME. A crisis in chronic pain care: an ethical analysis. Part two: proposed structure and function of an ethics of pain medicine. Pain Physician. 2008;11(5):589-595.

8. Giordano J. Changing the practice of pain medicine writ large and small through identifying problems and establishing goals. Pain Physician. 2006;9(4):283-285.

9. Saunders C. Care of the dying. Control of pain in terminal cancer. Nurs Times. 1959;23:1031-1032.

10. Saunders C. Drug treatment in the terminal stages of cancer. Curr Med Drugs. 1960;1(1):16-28.

11. Clark D. 'Total pain', disciplinary power and the body in the work of Cicely Saunders, 1958-1967. Soc Sci Med. 1999;49(6):727-736.

12. The American Academy of Pain Medicine Council on Ethics. The American Academy of Pain Medicine Ethics Charter: American Academy of Pain Medicine. 2003. Available from: http://www.painmed.org/files/ ethics-charter.pdf. Accessed December 21, 2017.

13. American Pain Society. Guidelines on the management of postoperative pain. J Pain. 2016;17(2):131-157.

14. Russell TL, Madsen RW, Flesner M, Rantz MJ. Pain management in nursing homes: what do quality measure scores tell us? J Gerontol Nurs. 2010;36(12):49-56.

15. Miu DKY, Chan KC. Under-detection of pain in elderly nursing home residents with moderate to severe dementia. J Clin Gerontol Geriatr. 2014;5(1):23-27.

16. Deandrea S, Montanari M, Moja L, Apolone G. Prevalence of undertreatment in cancer pain. A review of published literature. Ann Oncol. 2008;19(12):1985-1991.

17. Fisch MJ, Lee J, Weiss M, et al. Prospective, observational study of pain and analgesic prescribing in medical oncology outpatients with breast, colorectal, lung, or prostate cancer. J Clin Oncol. 2012;30(16): 1980-1988.

18. van den Beuken-van Everdingen MHJ, de Rijke JM, Kessels AG, Schouten HC, van Kleef M, Patijn J. Prevalence of pain in patients with cancer: a systematic review of the past 40 years. Ann Oncol. 2007;18(9): $1437-1449$

19. Te Boveldt N, Vernooij-Dassen M, Leppink I, Samwel H, Vissers K, Engels Y. Patient empowerment in cancer pain management: an integrative literature review. Psychooncology. 2014;23(11):1203-1211.

20. Pimentel CB, Briesacher BA, Gurwitz JH, Rosen AB, Pimentel MT, Lapane KL. Pain management in nursing home residents with cancer. JAm Geriatr Soc. 2015;63(4):633-641.

21. Quintero GA. Medical education and the healthcare system - why does the curriculum need to be reformed? BMC Med. 2014;12(1):213.

22. Buchman DZ, Ho A, Illes J. You present like a drug addict: patient and clinician perspectives on trust and trustworthiness in chronic pain management. Pain Med. 2016;17(8):1394-1406.

23. Kress HG, Ahlbeck K, Aldington D, et al. Managing chronic pain in elderly patients requires a CHANGE of approach. Curr Med Res Opin. 2014;30(6):1153-1164. 
24. Schreiber JA, Cantrell D, Moe KA, et al. Improving knowledge, assessment, and attitudes related to pain management: evaluation of an intervention. Pain Manag Nurs. 2014;15(2):474-481.

25. Manchikanti L, Falco FJ, Boswell MV, Hirsch JA. Facts, fallacies, and politics of comparative effectiveness study: part 2-implications for interventional pain management. Pain Physician. 2009;13(1): E55-E79.

26. King NB, Fraser V. Untreated pain, narcotics regulation, and global health ideologies. PLoS Med. 2013;10(4):e1001411.

27. Taylor AL, Lawrence OG, Katrina AP. Ensuring effective pain treatment: a national and global perspective. JAMA. 2008;299(1):89-91.

28. Pasero C, McCaffery M. Comfort-function goals: a way to establish accountability for pain relief. Am J Nurs. 2004;104(9):77-81.

29. McPherson CJ, Hadjistavropoulos T, Devereaux A, Lobchuk MM. A qualitative investigation of the roles and perspectives of older patients with advanced cancer and their family caregivers in managing pain in the home. BMC Palliat Care. 2014;13(1):39.

30. Schatman ME, Darnall BD. A pendulum swings awry: seeking the middle ground on opioid prescribing for chronic non-cancer pain. Pain Med. 2013;14(5):617.

31. Atkinson TJ, Schatman ME, Fudin J. The damage done by the war on opioids: the pendulum has swung too far. J Pain Res. 2014;7: 265-268.

32. Andrew R, Derry S, Taylor RS, Straube S, Phillips CJ. The costs and consequences of adequately managed chronic non-cancer pain and chronic neuropathic pain. Pain Pract. 2014;14(1):79-94.

33. Kress HG, Aldington D, Alon E, et al. A holistic approach to chronic pain management that involves all stakeholders: change is needed. Curr Med Res Opin. 2015;31(9):1743-1754.

34. Schatman ME, Lebovits AH. On the transformation of the "profession" of pain medicine to the "business" of pain medicine: an introduction to a special series. Pain Med. 2011;12(3):403-405.

35. Ferrell B, Dean GE. Ethical issues in pain management. J Palliat Care. 1994;10(3):67-72.

36. Borneman T, Ferrel B. Ethical issues in pain management. Clin Geriatr Med. 1996;12(3):615-628.

37. Ferrell BR, Novy D, Sullivan MD, et al; American Pain Society/ American Academy of Pain Ethics Task Force. Ethical dilemmas in pain management. J Pain. 2001;2(3):171-180.

38. Bernhofer E. Ethics and pain management in hospitalized patients. Online J Issues Nurs. 2011;17(1):11.

39. Sullivan M. Ethical principles in pain management. Pain Med. 2000;1(3):274-279.

40. Schatman ME. Psychological assessment of Maldynic pain: the need for a phenomenological approach. In: Giordano J, editor. Maldynia: Inter-Disciplinary Perspectives on the Illness of Chronic Pain. New York: Informa Healthcare; 2010:157-182.

41. World Health Organization [webpage on the Internet]. WHO Definition of Palliative Care. 2002. Available from: www.who.int/cancer/palliative/ definition/en/. Accessed January 2014.

42. Worldwide Palliative Care Alliance. Global Atlas of Palliative Care at the End of Life. London: Worldwide Palliative Care Alliance; 2014.

43. Knaul FM, Farmer PE, Bhadelia A, Berman P, Horton R. Closing the divide: the Harvard Global Equity Initiative-Lancet Commission on global access to pain control and palliative care. Lancet. 2015;386(9995):722-724.

44. Brennan F, Carr DB, Cousins M. Pain management: a fundamental right. Anesth Analg. 2007;105(1):205-221.

45. Schofferman J. PRF: too good to be true? Pain Med. 2006;7(5):395.

46. Emanuel EJ, Emanuel L. Four models of the physician-patient relationship. JAMA. 1992;267(16):2221-2226.

47. Charles C, Gafni A, Whelan T. Decision-making in the physician-patient encounter: revisiting the shared treatment decision-making model. Soc Sci Med. 1999;49(5):651-661.

48. Degner LF, Sloan JA. Decision-making during serious illness: what role do patients really want to play? J Clin Epidemiol. 1992;45(9): $941-950$
49. Austin W. The ethics of everyday practice: healthcare environments as moral communities. ANS Adv Nurs Sci. 2007;30(1):81-88.

50. Fox E. Predominance of the curative model of medical care. A residual problem. JAMA. 1997;278(9):761-763.

51. Vanlaere L, Gastmans C. A personalist approach to care ethics. Nurs Ethics. 2001;18(2):161-173.

52. Fry ST. The philosophical foundations of caring. In: Leininger MM, editor. Ethical and moral dimensions of care. Detroit: Wayne State University Press; 1990:13-24.

53. Sulmasy DP. Dignity and bioethics: history, theory, and selected applications. Human Dignity and Bioethics Essays Commissioned by the President's Council on Bioethics. President's Council on Bioethics, editor Washington, DC: 2008:476-480.

54. Oakley J, Cocking D. Virtue Ethics and Professional Roles. Cambridge: Cambridge University Press; 2001.

55. Pellegrino ED, Thomasma DC. Virtues in Medical Practice. Oxford: Oxford University Press; 1993.

56. Benner P. A dialogue between virtue ethics and care ethics. Theor Med. 1997;18(1-2):47-61.

57. World Health Organization. Strengthening of palliative care as a component of integrated treatment throughout the life course. J Pain Palliat Care Pharmacother. 2014;28(2):130-134.

58. Hernández-Marrero P, Martins Pereira S. A valence issue or a transformational definition: is palliative care no more, no less than highquality care? In: Małecka K, Gibbs R, editors. And Death Shall Have Dominion: Interdisciplinary Perspectives on Dying, Caregivers, Death, Mourning and the Bereaved. Oxford: Inter-Disciplinary Press; 2015: 61-71.

59. Nelson JE, Cortez TB, Curtis JR, et al. Integrating palliative care in the ICU: the nurse in a leading role. J Hosp Palliat Nurs. 2011;13(2): 89-94.

60. Bruera E, Hui D. Conceptual models for integrating palliative care at cancer centers. J Palliat Med. 2012;15(11):1261-1269.

61. Beider S. An ethical argument for integrated palliative care. Evid Based Complement Alternat Med. 2005;2(2):227-231.

62. Beauchamp TL, Childress JF. Principles of Biomedical Ethics. 5th ed. New York: Oxford University Press; 2001.

63. Scarry E. The Body in Pain. Oxford: Oxford University Press; 1985.

64. Charon R. Narrative medicine: form, function, and ethics. Ann Intern Med. 2001;134(1):83-87.

65. Charon R. Narrative and medicine. NEngl JMed. 2004;350(9):862-864

66. Pellegrino ED. The healing relationship: the architectonics of clinical medicine. In: Shelp EE, editor. The Clinical Encounter. The Moral Fabric of the Patient-Physician Relationship. Dordrecht: Springer; 1983:153-172.

67. Lebovits A. Ethics and pain: why and for whom? Pain Med. 2001;2(2): 92-96.

68. Johnson M, Collett B, Castro-Lopes JM. The challenges of pain management in primary care: a pan-European survey. J Pain Res. 2013;6: 393-401.

69. Tait RC. Vulnerability in clinical study with patients in pain: a risk analysis. J Law Med Ethics. 2009;37(1):59-72.

70. Kipnis K. Vulnerability in study subjects: a bioethical taxonomy. Ethical and Policy Issues in Study Involving Human Participants. Volume II: Commissioned Papers. Rockville, MD: National Bioethics Advisory Commission (NBAC); 2001:G1-G13.

71. ten Have H. Vulnerability: Challenging Bioethics. New York: Routledge; 2016.

72. Shapiro RS. Health care providers' liability exposure for inappropriate pain management. J Law Med Ethics. 1996;24(4):360-364.

73. Schatman ME. Pain and corporatization: more special interests, more disparities, more vulnerability. Pain Med. 2011;12(4):632-633.

74. Kaplan B, Echols M. 'One Health' - the Rosetta stone for 21 st century health and health providers. Vet Ital. 2009;45(3):377-382.

75. Osler W. Remarks on specialism. Boston Med Surg J. 1892;126:457-459.

76. Golden RL, Roland CG. Sir William Osler. San Francisco: Norman Publishing; 1988. 
77. John M. From Osler to the cone technique. HSR Proc Intensive Care Cardiovasc Anesth. 2013;5(1):57-58.

78. Loeser JD, Schatman ME. Chronic pain management in medical education: a disastrous omission. Postgrad Med. 2017;129(3):332-335.

79. Araújo J, Gomes CC, Jácomo A, Martins Pereira S. Teaching bioethics in high schools. Health Educ J. 2017;76(4):507-513.
80. Martins Pereira S, Teixeira CM, Carvalho AS, Hernández-Marrero P; InPalIn. Compared to palliative care, working in intensive care more than doubles the chances of burnout: results from a nationwide study. PLoS One. 2016;11(9):e0162340.

81. Magalhães S. Narrative in medicine and history: how fiction reminds us of who we are. Adv Soc Sci Res J. 2016;3(7):176-183.

\section{Publish your work in this journal}

The Journal of Pain Research is an international, peer reviewed, open access, online journal that welcomes laboratory and clinical findings in the fields of pain research and the prevention and management of pain. Original research, reviews, symposium reports, hypothesis formation and commentaries are all considered for publication.
Dovepress

The manuscript management system is completely online and includes a very quick and fair peer-review system, which is all easy to use. Visit http://www.dovepress.com/testimonials.php to read real quotes from published authors. 